\section{(C) OPEN ACCESS}

\title{
Takotsubo cardiomyopathy with severe bradyarrhythmia following epidural insertion
}

\author{
David T Gamble, ${ }^{1}$ Kara J Shuttleworth, ${ }^{1}$ Caroline Scally, ${ }^{2}$ Stephen J Leslie ${ }^{1,3}$
}

${ }^{1}$ Cardiac Unit, Raigmore Hospital, Inverness, UK

${ }^{2}$ University of Aberdeen, Aberdeen, UK

${ }^{3}$ Department of Diabetes \& Cardiovascular Science, University of the Highlands and Islands, The Centre for Health Science, Inverness, UK

\section{Correspondence to} Professor Stephen J Leslie, stephen.leslie@nhs.net

Accepted 11 October 2016

\section{SUMMARY}

We present a case of takotsubo cardiomyopathy (TTC) with ventricular stand still and atrioventricular block. TTC can mimic ST elevation myocardial infarction and heart failure, but in this case resulted in a severe cardiac conduction disorder and ventricular standstill. This is a recognised but unusual presentation and serves as a lesson to those undertaking anaesthetics to be vigilant for TTC.

\section{BACKGROUND}

Takotsubo cardiomyopathy (TTC) or 'apical ballooning syndrome' is a relatively new clinical condition first described in $1990 .{ }^{1}$ It is a form of non-ischaemic cardiomyopathy, typically, but not exclusively, characterised by transient left ventricular (LV) dysfunction of the mid-apical segment, associated with compensatory excessive contraction at the cardiac base and apical ballooning. Most patients present with chest pain and dyspnoea accompanied by ECG changes, consistent with myocardial infarction, cardiac enzyme release and normal coronary arteries. ${ }^{2}$ Other complications have also been described, including arrhythmias, ${ }^{3-5}$ cardiogenic shock, ${ }^{6}$ intraventricular thrombi ${ }^{7}$ and arterial embolism. ${ }^{8}$ TTC has a female predilection and is thought to occur due to a catecholamine surge following stressful physical or emotional events leading to coronary spasm, autonomic disturbance and microvascular impairment, although the precise pathophysiology remains unclear. ${ }^{4}$

\section{CASE PRESENTATION}

A 66-year-old woman with a history of melanoma was admitted for an elective left-sided open adrenalectomy to manage an adrenal mass. Shortly after an uncomplicated epidural insertion and before any surgical intervention, she developed profound bradycardia with asystole requiring cardiopulmonary resuscitation (CPR) including intravenous epinephrine $(0.5 \mathrm{mg})$ and atropine $(600 \mu \mathrm{g})$. There was prompt return of spontaneous circulation with spontaneous breathing shortly after CPR $(<1 \mathrm{~min})$ was started. The patient reported no preceding chest pain.

\section{INVESTIGATIONS}

An ECG at the time showed widespread Twave inversion and prolonged QT interval (figure 1A). These are well-recognised ECG changes in TTC but usually occur after 24-48 hours. Initial plasma troponin was undetectable (lower limit of detection $\leq 40 \mathrm{ng} / \mathrm{L}$ ) but was raised after 12 hours at $1275 \mathrm{ng} / \mathrm{L}$, other blood tests including haemoglobin, urea and electrolytes were within normal limits. An echocardiogram performed shortly after this episode showed apical akinesia resulting in moderate LV dysfunction with no significant valvular abnormality. The patient was subsequently transferred to the coronary care unit for further management and continuous ECG monitor. At this time, the ECG intermittently demonstrated complete heart block ( $\mathrm{CHB})$, with a ventricular escape rhythm of $30 \mathrm{bpm}$ (figure 1B). There were periods of asystole (up to $10 \mathrm{~s}$; figure 1C).

An invasive coronary angiogram showed normal coronary arteries. A repeat echocardiogram at 4 days showed complete recovery of LV function. The diagnosis of TTC was made.

Despite recovery of LV function, $\mathrm{CHB}$ was persistent.

\section{TREATMENT}

A dual-chamber rate responsive pacemaker was inserted without complication. The patient was discharged on day 5 .

\section{OUTCOME AND FOLLOW-UP}

Because of the pressing need for surgery, this was rescheduled in the subsequent 3 weeks and was uncomplicated other than a brief episode of nonsustained ventricular tachycardia postoperatively on the surgical high dependency ward. The cause of the adrenal mass was metastatic melanoma. Continued follow-up of the pacemaker (at 3 months) was unremarkable, with atrial pacing $1.3 \%$ and ventricular pacing $<1 \%$.

\section{DISCUSSION}

Arrhythmias are an increasingly recognised complication of TTC and include atrial fibrillation, ventricular tachycardia and conduction defects. ${ }^{3-6}$ Complete atrioventricular (AV) block is less common $(<5 \%)$ and the involvement of prolonged asystole rarer.

The underlying pathophysiology of bradyarrhythmias in TTC remains unclear; proposed mechanisms including reduced coronary blood flow to conduction pathways secondary to ventricular dyskinesia, catecholamine-induced coronary vasospasm (especially to right coronary artery) and conduction pathway fibrosis secondary to prolonged ischaemia. ${ }^{5}$ The pathophysiology of tachyarrhythmia is most likely a result of long QT as is commonly seen in TTC and catecholamine surge. In our case, it is possible that the administration of epinephrine during the brief cardiac arrest may have contributed to the development of TTC as this mechanism has been previously suggested. ${ }^{9}$ 

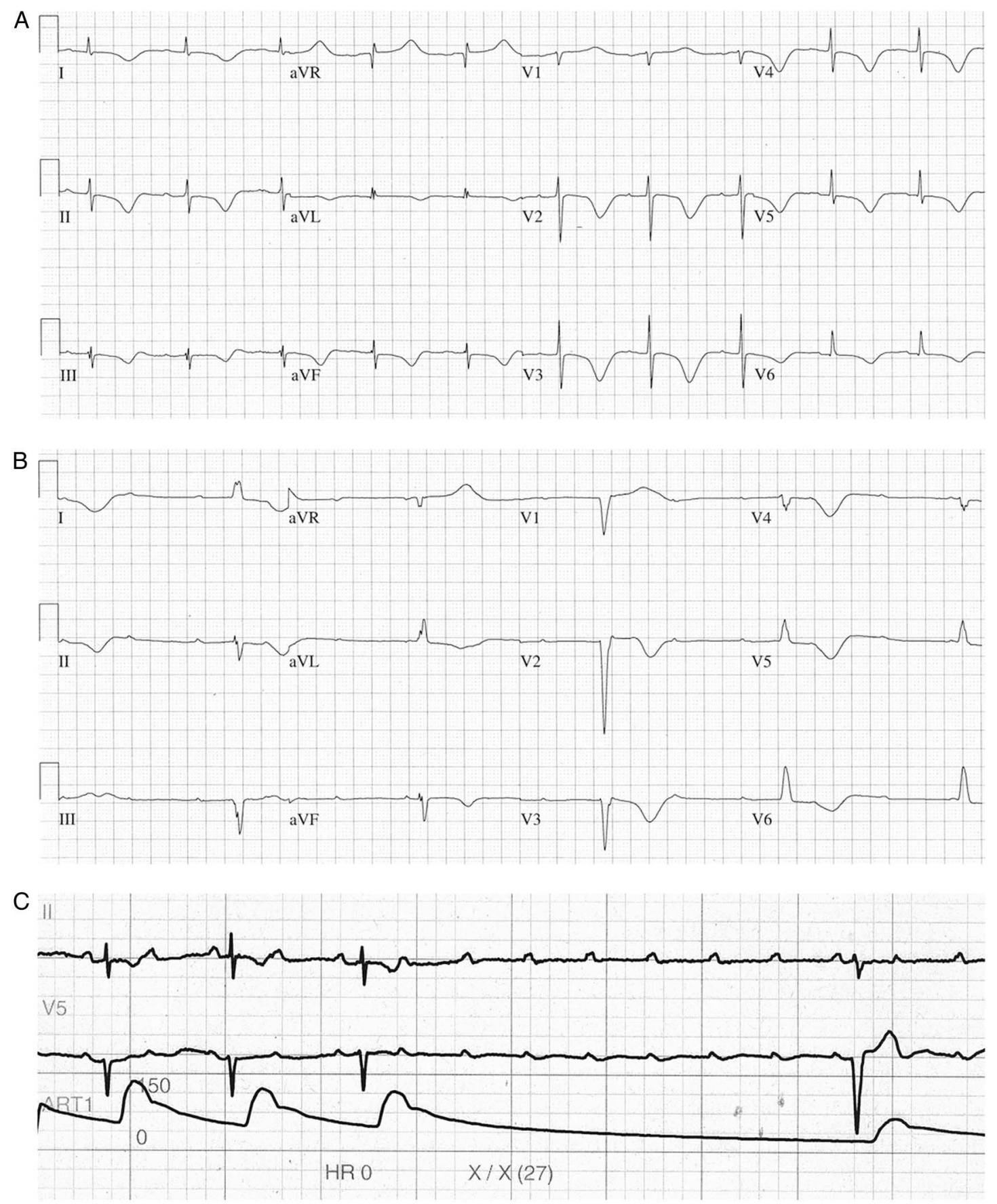

Figure 1 (A) Initial ECG showing widespread T wave inversion and QT interval prolongation. (B) ECG showing complete heart block with escape rhythm at $30 \mathrm{bpm}$. (C) Two lead rhythm strip and plethysmography trace showing ventricular asystole.

The correct management of TTC with complete AV block is uncertain and can be challenging. Literature on this subject is limited but recent studies have suggested that AV block persists despite resolution of the cardiomyopathy, and that permanent pacemaker implantation improves mortality in these patients. In our case, there was some time pressure due to the need for surgery and therefore early permanent pacemaker implantation was undertaken. ${ }^{4} 1011$

This case of ventricular asystole and cardiac arrest in the context of a TTC is unusual, and in this case mimicked a profound vasovagal episode triggered by an epidural insertion. The correct diagnosis was made with the use of early echocardiography and exclusion of coronary artery disease, in our case by conventional coronary angiography although one could argue that CT coronary angiography could be useful in such cases. Less invasive modalities such as CT coronary angiography would be appropriate in a clinical setting where ST elevation was not suspected. Cardiac MRI (CMR) would also be very important where clinical uncertainty or poor echo images resulting in diagnostic doubt. ${ }^{12} \mathrm{CMR}$ is a useful imaging modality in suspected TTC, as the absence of late gadolinium enhancement rules out a myocardial infarction and the presence of myocardial oedema can point to the diagnosis. If performed in the acute phase, CMR can also help differentiate between myocarditis 
and TTC. In this case, the profound bradycardia would have made MRI difficult and the need for permanent pacing would preclude MRI in the recovery phase.

The persistence of AV block and need for surgery mandated permanent pacemaker insertion. This case illustrates that anaesthetist should be vigilant for this increasing recognised cause of cardiovascular compromise and request an early echocardiogram in suspected cases. ${ }^{12}$

\section{Learning points}

- Takotsubo cardiomyopathy (TTC) is an increasingly recognised clinical condition.

- TTC can mimic other cardiac conditions and early investigation with echo and coronary imaging is important to avoid unnecessary therapy, for example, thrombolysis.

- Treatment of TTC is supportive.

- Recovery is usually good although recurrence can occur.

Contributors DTG was involved in the clinical care of this patient, and preparation of the first draft of this paper and subsequent review. KJS was involved in the clinical care of this patient, preparation of the first draft of this paper and subsequent review, and had major role in preparing the images. CS was involved in the review of the first draft and literature review. SJL was involved in the clinical care of this patient and had the idea for the case report and was involved at all stages of writing.

Competing interests None declared.

Provenance and peer review Not commissioned; externally peer reviewed.

Open Access This is an Open Access article distributed in accordance with the Creative Commons Attribution Non Commercial (CC BY-NC 4.0) license, which permits others to distribute, remix, adapt, build upon this work non-commercially, and license their derivative works on different terms, provided the original work is properly cited and the use is non-commercial. See: http://creativecommons.org/ licenses/by-nc/4.0/

\section{REFERENCES}

1 Sato $\mathrm{H}$, Tateishi $\mathrm{H}$, Uchida T. Takotsubo type cardiomyopathy due to multivessel spasm. In: Kodama KH, Hon H. eds. Clinical aspect of myocardial injury from ischemia to heart failure. Ka- gakuhyouronsya Tokyo, 1990:56-64.

2 Kurisu S, Sato H, Kawagoe T, et al. Tako-tsubo-like left ventricular dysfunction with ST-segment elevation: a novel cardiac syndrome mimicking acute myocardial infarction. Am Heart J 2002;143:448-55.

3 Yoshida T, Hibino T, Fujimaki T, et al. Transient mid-ventricular ballooning syndrome complicated by syncope: a variant of tako-tsubo cardiomyopathy. Int I Cardio/ 2009; 135:e20-3.

4 Korantzopoulos P, Nikas DN, Letsas K, et al. High-grade atrioventricular block and takotsubo cardiomyopathy: case report and review of the literature. Int Cardiovasc Res J 2015;9:119-24.

5 Limm BN, Hoo AC, Azuma SS. Variable conduction system disorders in takotsubo cardiomyopathy: a case series. Hawai J Med Public Health 2014;73:148-51.

6 Dib C, Prasad A, Friedman PA, et al. Malignant arrhythmia in apical ballooning syndrome: risk factors and outcomes. Indian Pacing Electrophysiol J 2008:8:182-92.

7 Haghi D, Papavassiliu T, Heggemann F, et al. Incidence and clinical significance of left ventricular thrombus in tako-tsubo cardiomyopathy assessed with echocardiography. QJM 2008;101:381-6.

8 Andò G, Saporito F, Trio 0, et al. Systemic embolism in tako-tsubo syndrome. Int J Cardiol 2009;134:e42-43.

9 Calvo-Taracido M, Almendro-Delia M, Garcia-Rubira J. Tako-tsubo syndrome after administration of intravenous adrenaline during atrioventricular block. Open J Emerg Med 2013;1:8-10.

10 Le MT, Grimard C, Varenne O, et al. Tako-tsubo cardiomyopathy and high-degree atrio-ventricular block: do we need to wait left ventricular function recovery to implant a pacemaker? Int J Cardiol 2014;176:e56-9.

11 Stiermaier T, Rommel KP, Eitel C, et al. Management of arrhythmias in patients with takotsubo cardiomyopathy: is the implantation of permanent devices necessary? Heart Rhythm 2016;13:1979-86.

12 Dastidar AG, Frontera A, Palazzuoli A, et al. TakoTsubo cardiomyopathy: unravelling the malignant consequences of a benign disease with cardiac magnetic resonance. Heart Fail Rev 2015;20:415-21.

Copyright 2016 BMJ Publishing Group. All rights reserved. For permission to reuse any of this content visit http://group.bmj.com/group/rights-licensing/permissions.

BMJ Case Report Fellows may re-use this article for personal use and teaching without any further permission.

Become a Fellow of BMJ Case Reports today and you can:

- Submit as many cases as you like

- Enjoy fast sympathetic peer review and rapid publication of accepted articles

- Access all the published articles

- Re-use any of the published material for personal use and teaching without further permission

For information on Institutional Fellowships contact consortiasales@bmjgroup.com

Visit casereports.bmj.com for more articles like this and to become a Fellow 